\title{
Measurement of cross linked fibrin derivatives in plasma: an immunoassay using monoclonal antibodies
}

\author{
AN WHITAKER, ${ }^{*}$ MJ ELMS,$\dagger$ PP MASCI, ${ }^{*}$ PG BUNDESEN, $\ddagger$ DB RYLATT, \\ AJ WEBBER, $\ddagger$ IH BUNCE†
}

From the *University of Queensland Department of Medicine, Princess Alexandra Hospital, Brisbane, the $\dagger$ Division of Haematology, Royal Brisbane Hospital, and the $\ddagger$ Centre for Applied Immunology, School of Health Science, Queensland Institute of Technology, Brisbane, Australia

SUMMARY Fibrinogen degradation, fibrin polymerisation, and the insertion of cross links into fibrin by fibrin stabilising factor lead to the appearance of new antigenic determinants. Antibodies against these antigenic sites may react specifically with the derivatives but not with the parent molecules. We have utilised a monoclonal antibody, which interacts with the cross linked fragment $\mathrm{D}$ dimer and related high molecular weight fibrin derivatives, to develop an enzyme immunoassay which measures cross linked fibrin derivatives in plasma and serum using $D$ dimer as standard. Mean concentration in plasma from normal subjects was $75 \mathrm{ng} / \mathrm{ml}$ with an upper limit of about $144 \mathrm{ng} / \mathrm{ml}$. Concentrations in patients with pulmonary embolism, deep venous thrombosis, arterial thromboembolism, and disseminated intravascular coagulation were raised in all cases. Confirmation of the specific increase of cross linked fibrin derivatives in patients with disseminated intravascular coagulation was obtained by parallel monitoring of their fibrin degradation products in serum using affinity chromatography and sodium dodecyl sulphate (SDS) polyacrylamide gel electrophoresis. In many patients the plasma concentrations greatly exceeded the serum values of cross linked fibrin degradation products, suggesting that the procedure can measure fibrin derivatives in plasma which are absent from serum.

The insertion of $\gamma-\gamma$ chain cross links into fibrin by fibrin stabilising factor $\left(\right.$ XIII $\left._{a}\right)$ generates new and probably unique antigenic deteminants, which can be detected in its plasminolytic cleavage products. ${ }^{2}$ Polyclonal antisera containing such antibodies have been exploited in differentiating between fragments derived from cross linked fibrin such as $D$ dimer ${ }^{13-5}$ or a family of high molecular weight fragments ${ }^{2}$ and those derived from fibrinogen and non-cross linked fibrin (fragments $\mathrm{X}, \mathrm{Y}, \mathrm{D}$, and E). Theoretically, such antisera, after differential absorption to remove panspecific antibodies, could be applied clinically to detect and measure cross linked fibrin derivatives. In practice this has proved difficult because of the low titres of the antibodies which remain after adsorption.

We have recently reported the development of two monoclonal antibodies which are monospecific for D dimer and other larger cross linked fibrin derivatives. ${ }^{6}$ One of these monoclonal antibodies (DD-1C3/28) was utilised in an enzyme immunoas-

Accepted for publication 24 April 1984 say to measure cross linked fibrin derivatives in serum. This procedure showed advantages over measurement of fibrin degradation products by either staphylococcal clumping tests or a latex procedure with antifibrinogen antiserum. ${ }^{7}$ With results expressed as D dimer equivalents, concentrations of fibrin derivatives of less than $200 \mathrm{ng} / \mathrm{ml}$ were found in normal sera while raised concentrations were found in most patients with deep venous thrombosis and pulmonary thromboembolism and in all patients with disseminated intravascular coagulation. In some patients increased concentrations were found using the monoclonal assay, although the other procedures gave results in the normal range. This assay could not, however, be utilised in the presence of large quantities of fibrinogen, which competed with the test molecules during the procedure.

Using the second of these monoclonal antibodies, coded DD-3B6/22, ${ }^{\circ}$ we have developed a similar $T$ enzyme immunoassay which is not influenced by fibrinogen and therefore can detect and measure $\stackrel{\odot}{\oplus}$ cross linked fibrin degradation products in either $\stackrel{\mathbb{Q}}{\Omega}$ plasma or serum. Compared with existing routine 
procedures to measure fibrin degradation products, these monoclonal assays could allow a more precise separation between normal and abnormal samples; they would be capable of differentiating between fibrinolysis and fibrinogenolysis; they offer the possibility of monitoring the release of thrombus products during thrombolytic treatment; they have a potential role for screening patients at risk of developing thrombosis or for monitoring anticoagulant treatment; and there is the possibility that they will detect soluble fibrin derivatives which, while present in plasma, are incorporated into the clot and are therefore not measured in assays used on serum. Such an assay could find wide usefulness in evaluating hypercoagulable states.

We report a preliminary assessment of this procedure. While values are quantitated as the standard D dimer, it is now known that these antibodies also react with other cross linked fragments and we prefer to group these collectively as cross linked fibrin derivatives.

\section{Material and methods}

The groups studied were as follows: (a) 25 healthy leucopheresis donors; (b) seven patients with venographically proved deep venous thrombosis; (c) 14 patients with pulmonary embolism, showing typical features on ventilation and diagnostic perfusion lung scans; (d) four patients with arterial thromboembolism (surgically proved); and (e) 28 patients with laboratory evidence of consumption coagulopathy, having diagnoses characteristically associated with disseminated intravascular coagulation. All patients in this group fulfilled the criteria for disseminated intravascular coagulation described by Whaun and Oski. ${ }^{8}$ Except for several patients in group (e) no cases from our previous report were included.? All patient groups were studied within $24 \mathrm{~h}$ of diagnosis. A further 50 healthy blood donors have been studied separately.

Citrated plasma was obtained by mixing blood $(4.5 \mathrm{ml})$ with $0.1 \mathrm{M}$ sodium citrate $(0.5 \mathrm{ml})$. Plasma was obtained by centrifuging at $2000 \mathrm{~g}$ for $30 \mathrm{~min}$. Aprotinin ( $500 \mathrm{kIU}$ ) (Trasylol, Bayer) was added after centrifugation to minimise deterioration on storage. Aliquots were frozen at $-20^{\circ} \mathrm{C}$ for up to four weeks, thawed at $37^{\circ} \mathrm{C}$, and assayed in batches for cross linked fibrin derivatives by enzyme immunoassay (see below). A coagulation profile (prothrombin time, activated partial thromboplastin time, thrombin time, and fibrinogen assay) was performed in group (e). The platelet count was determined using a Coulter particle counter (S plus IV).

Serum was obtained by clotting blood $(2 \mathrm{ml})$ with thrombin (20 IU) in the presence of soybean trypsin inhibitor (3670 NF units), using FDP tubes (Burroughs Wellcome). This serum was also used to assay soluble cross linked fibrin derivatives by the same method used with plasma.

Fibrinogen/fibrin degradation products were measured (1) by a latex procedure (Dade Latex Antifibrinogen); and (2) by sodium dodecyl sulphate (SDS) polyacrylamide gel electrophoresis (PAGE) ${ }^{9}$ following affinity gel separation using antifibrinogen serum coupled to cyanogen-bromide activated Sepharose 4B according to the method of Lane,$^{10}$ modified by increasing the incubation time to overnight at $4^{\circ} \mathrm{C}$ rather than $2 \mathrm{~h}$ at $37^{\circ} \mathrm{C}$ (group e). This resulted in almost complete recovery from serum.

\section{MATERIAL}

\section{Purified proteins}

The purification of fibrinogen, fragments XYDE, and the cross linked fragments $\mathrm{D}$ dimer, $\mathrm{D}$ dimer-E, and high molecular weight cross linked fibrin fragments has been described previously.' Protein determination was performed by the method of Rylatt and Parish." The preparation and properties of the monoclonal antibodies used in this study have also been described. ${ }^{6}$

\section{METHODS}

Immunoassay of cross linked fibrin fragments

Two monoclonal antibodies were selected for developing the enzyme immunoassay of cross linked fibrin derivatives. One (coded DD-3B6/22) was monospecific for an antigen expressed on $\mathrm{D}$ dimer and related complexes known to contain cross linked $\gamma-\gamma$ chains - for example, D dimer-E and high molecular weight complexes. It " performed efficiently as a capture antibody unlike the monoclonal antibody coded DD-1C3/108 used in the previous study. The other (coded DD-4D2/182) was panspecific, binding fibrinogen and both fibrinogen and fibrin degradation products, except purified $\mathrm{E}$ and degraded fragment $D\left(D_{p}\right)$.

These antibodies were utilised in a capture-tag situation using the monospecific antibody DD$3 \mathrm{~B} 6 / 22$ as the capture antibody on a solid phase consisting of round bottomed 96 well polyvinyl microtitre plates (Dynatech). Fifty microlitres of monoclonal antibody DD-3B6/22 $(10 \mu \mathrm{g} / \mathrm{ml}$ in $0.1 \mathrm{M}$ carbonate coupling buffer $\mathrm{pH} 9 \cdot 6$ ) was bound to the plate for $1 \mathrm{~h}$ at room temperature. Each subsequent incubation step was carried out at room temperature followed by four washes using phosphate buffered saline ( $\mathrm{pH} \mathrm{7.4)}$ containing $0.2 \%$ Tween 20 and $0.5 \mathrm{M} \mathrm{NaCl}$ (PBS/T/S). After incubation for $1 \mathrm{~h}$ with test plasma or serum $(50 \mu \mathrm{l})$ diluted in $\mathrm{PBS} / \mathrm{T} / \mathrm{S}$ (1/5 for group (a) and 1/10 for all others), $50 \mu \mathrm{l}$ of horseradish peroxidase labelled monoclonal anti- 
body DD-4D2/182 $(1 \mu \mathrm{g} / \mathrm{ml}$ in PBS/T/S) was added and left for $1 \mathrm{~h}$. The colour reaction was developed for $10 \mathrm{~min}$ using $100 \mu \mathrm{l}$ of $\mathrm{H}_{2} \mathrm{O}_{2} / \mathrm{O}^{\prime}$ tolidine dihydrochloride and stopped with $50 \mu \mathrm{l}$ of $3 \mathrm{~N} \mathrm{HCl}$. The chromogen was prepared immediately before use by adding $10 \mu \mathrm{l}$ of $3 \% \mathrm{H}_{2} \mathrm{O}_{2}$ to $10 \mathrm{ml}$ of the O' tolidine solution comprising $10 \mathrm{mM}$ citrate, $2.5 \mathrm{mM}$ O' tolidine dihydrochloride, and $0.025 \mathrm{mM}$ EDTA, $\mathrm{pH} \mathrm{4.5}$. Absorbance was read at $405 \mathrm{~nm}$ using a microtitre plate reader (Titertek Multiskan Model MC, Flow Laboratories). Assay values were interpolated from a standard curve using concentrations of D dimer (0-1000 $\mathrm{ng} / \mathrm{ml})$. Samples with concentrations greater than $10000 \mathrm{ng} / \mathrm{ml}$ were further diluted to provide readings on the linear portion of the standard curve.

\section{Results}

Fig. 1 shows representative binding curves. All cross linked fibrin derivatives interacted, the highest affinity being found with $\mathrm{D}$ dimer. The affinity for other cross linked complexes (D dimer-E and high molecular weight derivatives) was several times lower. There was no binding to fibrinogen degradation products at concentrations up to $20 \mu \mathrm{g} / \mathrm{ml}$ or to fibrinogen up to $1 \mathrm{mg} / \mathrm{ml}$. Initially, fibrinogen showed some binding at high concentrations, but on critical study traces of $\gamma-\gamma$ cross links were found to be present. On removal of cross linked contaminants by solid phase adsorption with monospecific antibody, fibrinogen proved to be non-reactive.

Plasma concentrations of cross linked fibrin derivatives in the study groups (Fig. 2) showed a similar pattern of distribution as reported previously

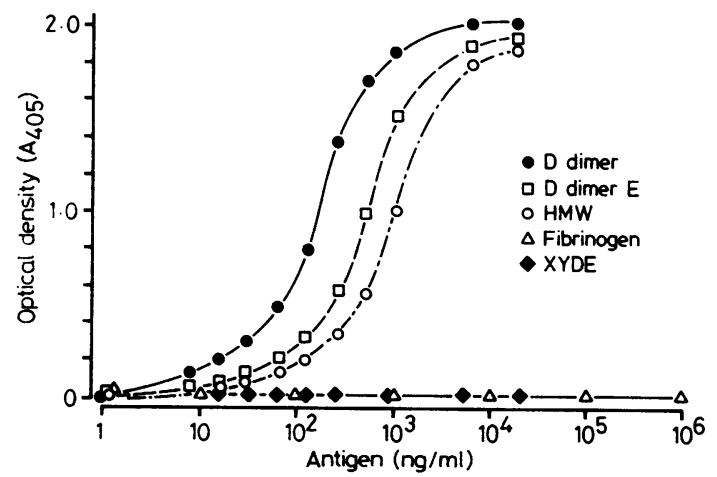

Fig. 1 Binding curves of fibrinogen, a fibrinogen lysate ( $X$, $Y, D, E)$, and the cross linked derivatives $D$ dimer, $D$ dimer-E, and a high molecular weight lysate. Trace contaminants were removed from fibrinogen by adsorption with the monoclonal antibody $D D-3 B 6 / 22$.

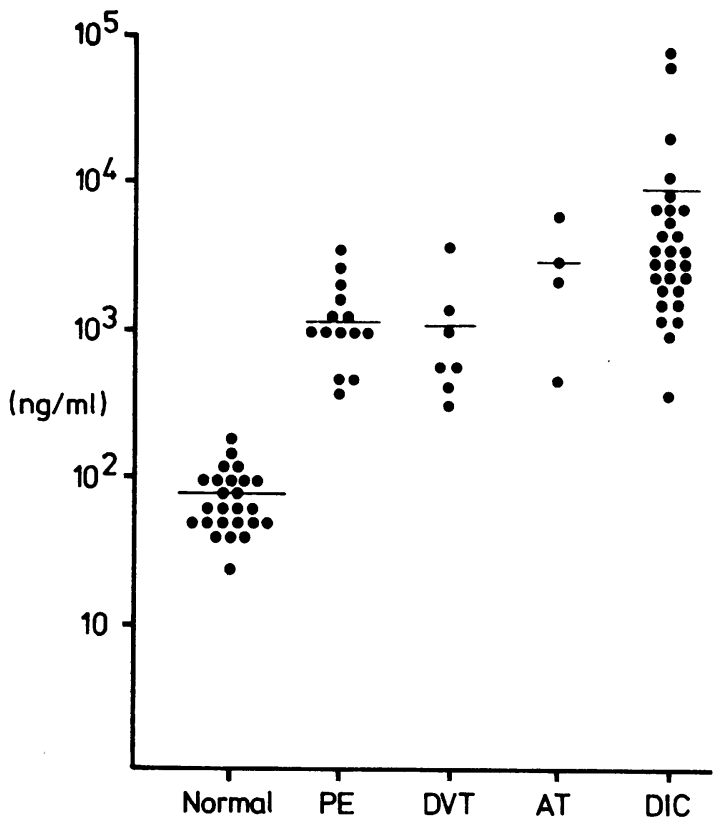

Fig. 2 Determinations of cross linked fibrin derivatives (using a $D$ dimer standard) in normal subjects and patient groups. PE: pulmonary embolus; DVT: deep venous thrombosis; $A T$ : arterial thromboembolism; DIC: disseminated intravascular coagulation. Horizontal lines indicate the arithmetic means (data plotted logarithmically).

with a serum assay, ${ }^{7}$ although with a slightly lower range. All patient groups were clearly different from the control group, without overlapping. Mean values (calculated arithmetically) were as follows: normal $75 \mathrm{ng} / \mathrm{ml}$; pulmonary embolism $1251 \mathrm{ng} / \mathrm{ml}$; deep venous thrombosis $1096 \mathrm{ng} / \mathrm{ml}$; arterial thromboembolism $2817 \mathrm{ng} / \mathrm{ml}$; disseminated intravascular coagulation $8259 \mathrm{ng} / \mathrm{ml}$. The wide scatter of results precludes any useful parametric analysis of the data. Other groups of normal plasmas (including healthy blood donors) have been assayed, agreeing with the values shown in Fig. 2, and the normal range has been provisionally established as below $144 \mathrm{ng} / \mathrm{ml}$.

With SDS PAGE (Fig. 3) bands identifiable as cross linked fibrin fragments were found in serum of all but two of 28 patients with disseminated intravascular coagulation. The two exceptions had the lowest concentrations of fibrin derivatives assayed in plasma. Cross linked fibrin fragments can similarly be identified in the sera of some patients with deep venous thrombosis and pulmonary embolism. Since these patients have lower concentrations of fibrin degradation products the technique is not sufficiently sensitive to be applied routinely. When used to monitor the increased concentrations of fibrin degradation products during thrombolytic 


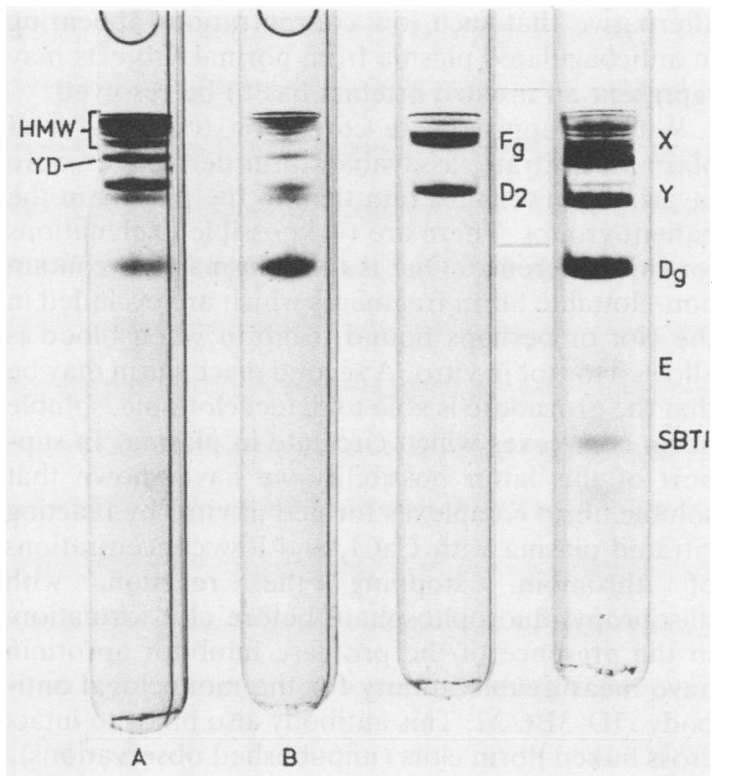

Fig. 3 Serum fibrin degradation product patterns on SDS $P A G E$ from two patients with disseminated intravascular coagulation. A: promyelocytic leukaemia; $B$ : acute pancreatitis. High molecular weight fragments are bracketed and $Y D$ has a similar mobility to $X$. The marker gels include fibrinogen $(F g), D$ dimer $\left(D_{2}\right)$, fibrinogen fragments $(X, Y$, $D g, E)$, and soya bean trypsin inhibitor (SBTI). Fibrin degradation products in the patients are identified as predominantly cross linked species plus some $Y$ and $D$.

treatment (Fig. 4) both SDS PAGE and enzyme immunoassay can distinguish between cross linked fibrin fragments and fibrinogen degradation products.

Serum concentrations of fibrin degradation products (Dade procedure) were increased in all cases of disseminated intravascular coagulation (mean $167 \mu \mathrm{g} / \mathrm{ml})$. They were also raised in 10 of 14 patients with pulmonary embolism (71\%) and two of seven patients with deep venous thrombosis, contrasting with the finding of increased concentrations of cross linked fibrin derivatives in all cases.

With few exceptions (studying 45 patients in groups b-e) serum values were appreciably lower than plasma values of fibrin derivatives (Fig. 5). The scatter of points suggests two populations: one where serum and plasma values are identical and another where plasma values average twice those in serum. Plasma values were not corrected for dilution by citrate anticoagulant. Plasma values also exceeded those in serum in most healthy control subjects.

The conditions of the assay described here permit the detection of concentrations of $\mathrm{D}$ dimer down to
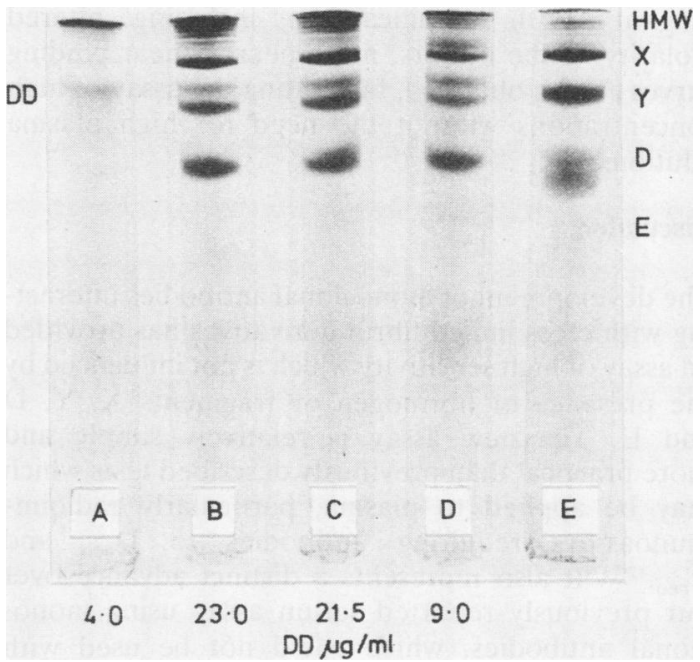

Fig. 4 Serum fibrin degradation product patterns on SDS $P A G E$ from a patient with iliofemoral venous thrombosis before and during streptokinase administration. $A$ : pretreatment; B: day 1; C: day 2; D: day 3. E is a marker gel. Small amounts of $D$ dimer $(D D)$ and high molecular weight species were identified in the initial sample. During thrombolysis considerable amounts of fibrinogen fragments (XYDE) appeared. The increased concentrations of cross linked species also seen were assayed as $D$ dimer by enzyme immunoassay. ${ }^{7}$

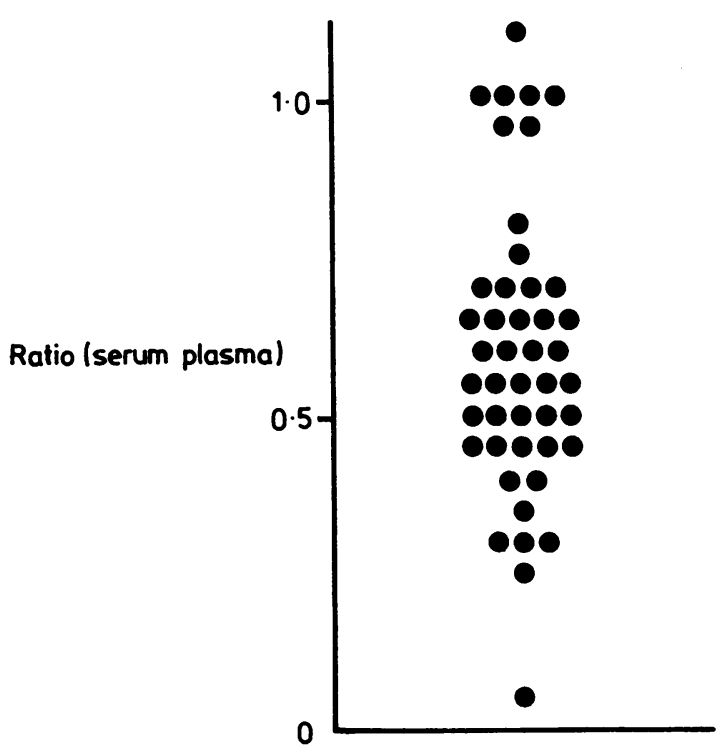

Fig. 5 The serum/plasma ratios of cross linked fibrin derivatives in the patient groups. On adjusting for dilution of plasma by anticoagulant solution, concentrations in native plasma exceeded those in serum in all cases. 
$1 \mathrm{ng} / \mathrm{ml}$. With modifications, including altered molarity of the buffers, more nearly linear binding curves can be obtained, facilitating the assay of high concentrations without the need for high plasma dilutions.

\section{Discussion}

The development of monoclonal antibodies interacting with cross linked fibrin derivatives has provided an assay of high sensitivity which is not influenced by the presence of fibrinogen or fragments $\mathrm{X}, \mathrm{Y}, \mathrm{D}$ and $E$. The new assay is relatively simple and more practical than previously described tests which may be applied to plasma, particularly radioimmunoassays requiring antibodies to $D_{\text {neo }}$ and $\mathrm{E}_{\text {neo. }} \cdot{ }^{1213}$ It also represents a distinct advance over our previously reported serum assay using monoclonal antibodies, which could not be used with plasma. ${ }^{7}$ Fibrinogen interfered in the earlier assay because it was necessary to use a panspecific antibody for capture. In this present modification, the monospecific monoclonal antibody DD-3B6/22 behaved efficiently as a capture antibody, allowing the panspecific monoclonal antibody to be used as the tag material. The sensitivity down to at least $1 \mathrm{ng} / \mathrm{ml}$ is also a further advance over the previous method, permitting accurate measurements in all normal plasmas. Both assays can, however, be applied to serum specimens, and unlike assays utilising conventional polyclonal antibodies, they effectively distinguish between the breakdown products of cross linked fibrin and those of fibrinogen (see Fig. 1).

The preliminary clinical data provided on patients with proved intravascular coagulation or thrombosis confirm the sensitivity of the procedure and also suggest high specificity. There was no overlap with the normal range in patients with deep venous thrombosis or pulmonary embolism. Conversely, many with deep venous thrombosis gave normal fibrin degradation product assays using a conventional latex procedure. The potential of this assay as a screening test for thrombosis will need to be evaluated by further trials, but, at this point, it would seem to be useful in discriminating between patients with and without thrombosis.

The concentrations found in normal plasma were higher than those measured in serum. These values probably represent the presence of traces of cross linked fibrin derivatives because they can be completely removed from plasma by absorption with the monoclonal antibody DD-3B6/22 bound to Sepharose 4B. The possibility that these cross linked fibrin derivatives are present in vivo as the result of normal fibrinolysis must remain a speculation. The alternative that such low concentrations appearing in anticoagulated plasma from normal subjects may represent an in vitro artefact has to be resolved.

With an approximate correction for dilution of plasma by citrate, assayable fibrin derivatives were invariably lower in serum than in the plasma in the patient groups. There are two possible explanations for this difference. One is that plasma may contain non-clottable fibrin fragments which are occluded in the clot or perhaps bound to fibrin when blood is allowed to clot in vitro. A second mechanism may be that the procedure is able to detect clottable, soluble fibrin complexes which circulate in plasma. In support of this latter possibility we have shown that soluble fibrin complexes formed in vitro by reacting citrated plasma with $\mathrm{CaCl}_{2}$ and low concentrations of thrombin, stopping the reaction with diisopropyl-fluorophosphate before clot formation, in the presence of the protease inhibitor aprotinin have measureable affinity for the monoclonal antibody DD-3B6/22. This antibody also binds to intact cross linked fibrin clots (unpublished observations).

The antibody (DD-3B6/22) has only low affinity for carboxymethylated $\gamma-\gamma$ chains. The implication is that it recognises a conformation resulting from the juxtaposition of two $D$ domains of adjacent fibrin molecules and that it may not necessarily be specific for the presence of $\gamma-\gamma$ cross links. After plasmin degradation, however, DD-3B6/22 will react only with cross linked fibrin fragments and complexes. If these findings are substantiated then DD-3B6/22 assays of serum and plasma performed in tandem will be complementary. The serum level will determine the presence of non-clottable cross linked degradation products, and the excess in plasma may be a measure of circulating soluble fibrin. The combination may offer a new tool for evaluating hypercoagulable states.

The choice of D dimer as the standard reference antigen probably results in lower estimates of cross linked fibrin derivatives than actually exist in plasma and serum, which contain mainly $\mathrm{D}$ dimer-E and larger complexes. ${ }^{9}$ These have lower affinity for the antibody than D dimer (see Fig. 1). D dimer is currently favoured as the standard because it is readily purified, although long term stability is doubtful. Preparations of high molecular weight complexes are being studied as possible alternatives to $D$ dimer.

The desirability of a practical assay specific for cross linked fibrin derivatives was first noted by Gaffney, ${ }^{14}$ but the end has been difficult to realise. Polyclonal antibodies which are monospecific for cross linked fibrin fragments have been reported.' It would seem, however, that only monoclonal technology will provide antibodies specific for cross 
linked fibrin in sufficient quantities to be exploited in clinically useful assays. Since enzyme immunoassay is becoming increasingly popular, the procedure reported here could be applied clinically. Furthermore, latex procedures utilising the monoclonal antibodies DD-3B6/22 and DD-1C3/28 have been developed and promise a useful alternative, where speed is required although with some loss of sensitivity and precision.

This study was supported by grants from the University of Queensland, the National Health and Medical Research Council of Australia, and the Lions Kidney and Medical Research Foundation. The monoclonal antibodies were provided by MAbCo, Division of Fielder-Gillespie Pty Ltd, Sydney.

\section{References}

' Budzynski AZ, Marder VJ, Parker ME, Shames P, Brizuela BS, Olexa SA. Antigenic markers on fragment DD: A unique plasmic derivative of human crosslinked fibrin. Blood 1979; 54:794-804.

${ }^{2}$ Gaffney PJ. Molecular aspects of fibrinolysis. Ann NY Acad Sci 1981;370:551-67.

${ }^{3}$ Lee-Own V, Gordon YB, Chard T. The detection of neoantigenic sites on the $\mathrm{D}$-dimer peptide isolated from plasmin digested cross linked fibrin. Thromb Res 1979;14:77-84.

4 Purves LR, Lindsey GG, Franks JJ. Sites of D-domain interaction in fibrin-derived D-dimer. Biochemistry 1980; 19:4051-8.
${ }^{5}$ Cierniewski CS, Janiak A, Nowak P, Augustyniak W. Reactivity of fibrinogen derivatives with antisera to human fibrin D-dimer and its $\gamma-\gamma$ chain remnant. Thromb Haemostas 1982;48:33-7.

- Rylatt DB, Blake AS, Cottis LE, et al. An immunoassay for human D dimer using monoclonal antibodies. Thromb Res 1983;31:767-78.

' Elms MJ, Bunce IH, Bundesen PG, et al. Measurement of crosslinked fibrin degradation products-an immunoassay using monoclonal antibodies. Thromb Haemostas 1983;50:591-4.

${ }^{8}$ Whaun JM, Oski FA. Experience with disseminated intravascular coagulation in a children's hospital. Can Med Assoc J 1972; 107:963-7.

- Whitaker AN, Rowe EA, Masci PP, Gaffney PJ. Identification of $D$ dimer-E complex in disseminated intravascular coagulation. Thromb Res 1980; 18:453-9.

${ }^{10}$ Lane DA, Robbins PA, Rampling MW, Kakkar VV. SDS polyacrylamide gel characterization of serum FDP produced in response to ancrod and streptokinase/plasminogen infusions in man. Br J Haematol 1977; 36: 137-48.

" Rylatt DB, Parish CR. Protein determination on an automatic spectrophotometer. Anal Biochem 1982;121:213-4.

${ }^{12}$ Gordon YB, Martin MJ, Langdon J, Chard T. The development of radioimmunoassays for fibrinogen degradation products: Fragments D and E. Br J Haematol 1975;29:109-19.

${ }^{13}$ Chen JP, Schulof RS. Radioimmunoassay of fibrinogen-fibrin degradation products: Assay for fragment E-related neoantigen-methodological aspects. Thromb Res 1979; 16:601-15.

14 Gaffney PJ, Brasher M. Subunit structure of the plasmin-induced degradation products of crosslinked fibrin. Biochim Biophys Acta 1973;295:308-13.

Requests for reprints to: Mr MJ Elms, Division of Haematology, Royal Brisbane Hospital, Bowen Bridge Road, Herston, Brisbane 4006, Australia. 